IZA DP No. 4181

The Efficient and Fair Approval of

"Multiple-Cost - Single-Benefit" Projects

under Unilateral Information

Nava Kahana

Yosef Mealem

Shmuel Nitzan

May 2009 


\title{
The Efficient and Fair Approval of "Multiple-Cost - Single-Benefit" Projects under Unilateral Information
}

\author{
Nava Kahana \\ Bar-Ilan University \\ and IZA \\ Yosef Mealem \\ Netanya Academic College \\ Shmuel Nitzan \\ Bar-Ilan University
}

Discussion Paper No. 4181

May 2009

IZA
P.O. Box 7240
53072 Bonn
Germany

Phone: +49-228-3894-0

Fax: +49-228-3894-180

E-mail: iza@iza.org

\begin{abstract}
Any opinions expressed here are those of the author(s) and not those of IZA. Research published in this series may include views on policy, but the institute itself takes no institutional policy positions.

The Institute for the Study of Labor (IZA) in Bonn is a local and virtual international research center and a place of communication between science, politics and business. IZA is an independent nonprofit organization supported by Deutsche Post Foundation. The center is associated with the University of Bonn and offers a stimulating research environment through its international network, workshops and conferences, data service, project support, research visits and doctoral program. IZA engages in (i) original and internationally competitive research in all fields of labor economics, (ii) development of policy concepts, and (iii) dissemination of research results and concepts to the interested public.
\end{abstract}

IZA Discussion Papers often represent preliminary work and are circulated to encourage discussion. Citation of such a paper should account for its provisional character. A revised version may be available directly from the author. 
IZA Discussion Paper No. 4181

May 2009

\begin{abstract}
The Efficient and Fair Approval of "Multiple-Cost - Single-Benefit" Projects under Unilateral Information*

This paper focuses on indivisible multiple-cost-single-benefit projects that must be approved by the government. A simple mechanism is proposed that ensures an efficient and fair implementation of such projects. The proposed mechanism is appropriate for a unilateral information structure: the single beneficiary has complete information on the cost and benefit of the project while the government official has no such information and the cost bearers have information only on each other's costs.
\end{abstract}

JEL Classification: D61, D62, D78

Keywords: indivisible project, single beneficiary, multiple-cost bearers, unilateral information, efficient and fair implementation

Corresponding author:

Nava Kahana

Department of Economics

Bar-Ilan University

52900 Ramat-Gan

Israel

E-mail:kahanan@mail.biu.ac.il

\footnotetext{
Kahana and Nitzan acknowledge generous financial support from the Adar Foundation of the Economics Department of Bar-Ilan University.
} 


\section{Introduction}

Consider a regulated economy in which the undertaking of a specific indivisible project that yields a net benefit to a single player and inflicts costs on the other players requires the approval of the government (bureaucrat). The beneficiary typically applies to the government official (bureaucrat) in order to obtain a license to undertake the project. For example, a company applies to the Environmental Protection Agency (EPA) for a license to construct a new plant that will produce pollution; a telecommunication company applies to the City Council for permission to site communication towers and antennas near or in the city; an employer applies to the Immigration and Naturalization Service (INS) for a visa to bring in a foreign worker; a family applies for a license to extend its house; and a taxi driver applies to the Ministry of Transportation for permission to operate a taxi. The problem of the government official is two-fold: first, should the project be approved and second, if it is, how can it be fairly implemented. The bureaucrat's objective then is to achieve an efficient and equitable outcome. This objective is especially challenging in situations where the bureaucrat has no information on either the benefit or the cost of the project, while such information is available to the single beneficiary of the project and partly available to the other players. Specifically, the players who are adversely affected by the project are only aware of each other's costs, but have no information on the benefit and cost to the single beneficiary. Implementation theory distinguishes between two distinct scenarios: complete-information environments and incompleteinformation environments. In both scenarios, the regulator is ignorant about the environment. In the complete-information setting, all players know the environment while in the incomplete-information setting, players can possess private information such that a player may not know the true environment either. In our setting, no information is available to the government official while there is information asymmetry between the beneficiary of the project and the other players, i.e., the information structure is unilateral rather than bilateral. The objective of this paper is to propose a new and simple mechanism that induces the beneficiary to apply for and undertake the project only if her/his net benefit from the project outweighs the cost it imposes on the other players. Furthermore, the proposed mechanism also induces the beneficiary to fully compensate each of the adversely affected individuals and therefore ensures efficiency and fairness. 
The project that we focus on can be viewed as a discrete private good that involves negative externalities. Accordingly, the main problem is how to ensure the efficient and fair production of this good in a regulated environment. There are three well-known classes of solution to the problem of externalities; however, given our particular setting, only one is applicable. One class of solutions, which is associated with Arrow (1970), involves the creation of a competitive market for the externality. An example would be a competitive market for pollution permits (see, for example, Kwerel, 1977; Lewis and Sappington, 1995; Duggan and Roberts, 2001a, 2002; English and Yates, 2007; and Kahana et al., 2008). However, in our case the market is not competitive since it involves only one participant - the single beneficiary. A second class of solutions, which is associated with Pigou (1920), involves intervention by a regulator who imposes a Pigovian tax. The absence of information and the discrete nature of the project exclude the imposition of such a tax in our case. The third class of solutions, which is associated with Coase (1960) and which is indeed relevant to our setting, involves negotiation between the players on appropriate compensation. Coase claims that if transaction costs are zero and property rights are well-defined, players should be able to negotiate their way to an efficient outcome. But this is an incomplete solution to the problem of externalities since Coase does not describe a specific mechanism for negotiation. Varian's (1994) compensation mechanism provides a structure for such negotiation under "bilateral” information in a continuous setting. Our mechanism can also be viewed as being complementary to Coase’s approach under “unilateral” information in a dichotomous setting. In Varian's compensation mechanism, the polluting plant already exists and the main issue is how to regulate the level of pollution (production). In our setting, the main issue is whether to allow the construction of a polluting plant. In Varian's compensation mechanism, those who are harmed are just compensated on the margin for the cost imposed on them, whereas under our mechanism they are fully compensated. In a marginal context, fairness cannot be attained; in our setting it can.

Most of the attempts to find solutions to the problem of externalities can be viewed as relating to a problem that arises in the presence of public goods. In the particular externality problem under consideration, the public good is an indivisible mixed public-private good. The provision is mixed because although the government is responsible for approving the project, the beneficiary has to voluntarily and privately apply for the approval and she/he (rather than the government) is solely 
responsible for its financing. The project is a public good because its undertaking affects (positively or negatively) the utility of all the players. There is a vast literature on the analysis of voluntary contribution games with discrete public goods (see, for example, Palfrey and Rosenthal, 1984; Gradstein and Nitzan, 1990; Admati and Perry, 1991; Bagnoli and Lipman, 1989, 1992; and Jackson and Moulin, 1992). The proposed voluntary contribution mechanism can implement the first-best outcome when individuals have certain knowledge of the threshold level of contributions needed for provision. However, in that setting all the players benefit from the project and thus the major issue is how to design an appropriate cost-sharing rule. In contrast, in our specific class of problems, there is only a single private beneficiary who is responsible for funding the project and therefore the challenge is to design a simple mechanism that efficiently and equitably implements the project. Note that Clarke (1971)'s well-known demand-revealing mechanism can also be applied in cases where some players are harmed by the project. However, it fails to achieve efficiency since it requires the levying of taxes that must then be wasted. Other mechanisms as well suffer from this shortcoming (see for instance Groves, 1973). Our mechanism is balanced in equilibrium though not out of equilibrium. Moore and Repullo (1988) and Abreu and Sen (1990) among others demonstrate that in economic environments, almost any choice rule can be implemented by multistage games and subgame-perfect equilibria. However, as Moore and Repullo pointed out, " ... the mechanisms we construct ....are far from simple....We present such mechanisms to show what is possible, not what is realistic." They also show that in certain cases it is possible to use somewhat simpler mechanisms. Maniquet (2003) characterizes the family of allocation rules that can be implemented in economic environments by a sequential Divide-and-Challenge perfect information mechanism. His mechanism is general and rather complicated. ${ }^{1}$ Furthermore, it does not generalize to cover the 2- player case, a notably difficult one for implementation. The mechanism proposed for the specific economic environments on which we focus is relatively simple, more realistic and covers the 2- player case.

The particular setting on which we focus is presented in Section 2. A simple two-player version (one beneficiary and one cost-bearer) of the proposed mechanism

\footnotetext{
${ }^{1}$ Earlier, Herrero and Srivastava (1992) have also characterized the class of social choice rules implementable through finite perfect information mechanisms. Due to complexity, it is very hard to compare the conditions in both papers,
} 
is described in Section 3. The general mechanism that ensures efficient and fair approval of indivisible multiple-cost-single-benefit projects under unilateral information is presented in Section 4. The last section contains brief concluding remarks.

\section{The setting}

One individual, indexed $a$, applies to the government official for receiving a license to undertake an indivisible project. The net benefit (net of the cost related to carrying out the project) in monetary terms that Player $a$ receives from the project is $V_{a} \in \mathfrak{R}_{+}$. But by carrying out this project Player $a$ imposes costs on $N$ individuals in the environment. The cost imposed on individual $i \in N$ is $V_{i} \in \mathfrak{R}_{+}$(the neighbors of the extended house, the producers and consumers affected by the new plant, local workers whose wages decline or, more generally, players whose utility decrease as a result of entry of new foreign workers, the existing taxi owners who face more competition or consumers suffering from increased pollution). These costs are common knowledge among all the individuals including the beneficiary Player $a$, but are unknown to the social planner. The informational structure is unilateral in the sense that, whereas the beneficiary knows the costs of the $N$ individuals opposing the approval of Player $a$ 's application, the latter, as well as the government official, do not know Player $a$ 's net benefit (benefit and costs).

An outcome in our setting is represented by a vector $x=\left(d, T_{1}, \ldots, T_{N}\right)$, where $d=\{1,0\}$ is a dichotomous decision variable; $d=1$ means approval and $d=0$ means disapproval, and $T_{i} \in \mathfrak{R}_{+}$is the monetary transfer from Player $a$ to Player $i$. The set of outcomes is then:

$$
X=\left\{\left(d, T_{1}, \ldots, T_{N}\right): d \in\{0,1\}, T_{i} \in \mathfrak{R}_{+}, \forall i\right\} .
$$

Player i's payoff (utility) function $U_{i}: X \times V_{i} \rightarrow \mathfrak{R}$ is quasi-linear ${ }^{2}$, that is:

$U_{i}\left(x, V_{i}\right)=T_{i}-d V_{i} \quad, \forall i$

and

\footnotetext{
${ }^{2}$ The quasi-linearity assumption is common in the public economics literature, especially in the context of voluntary provision of public goods and demand revealing mechanisms, see, for example, Clarke (1971), Groves (1976), Bagnoli and Lipman (1989), Jackson and Moulin (1992) and Mutuswami and Winter (2004).
} 
$U_{a}\left(x, V_{a}\right)=d V_{a}-\sum_{i=1}^{N} T_{i}$

A social choice function $f: V_{a} \times V_{1} \times \ldots \times V_{N} \rightarrow X$, assigns to each possible profile of the players' values an outcome $f(V) \in X$.

A function $f$ is efficient if for no profile $V$ there exists a vector $x \in X$, such that, $U_{a}\left(x, V_{a}\right) \geq U_{a}\left(f(V), V_{a}\right)$ and $U_{i}\left(x, V_{i}\right) \geq U_{i}\left(f(V), V_{i}\right), \forall i$ and $\exists i$ such that, $U_{i}\left(x, V_{i}\right)>U_{i}\left(f(V), V_{i}\right)$ or $U_{a}\left(x, V_{a}\right)>U_{a}\left(f(V), V_{a}\right)$. It can be easily shown that $f$ is efficient if:

$$
d(V)=\left\{\begin{array}{c}
1 \text { if } V_{a}-\sum_{i=1}^{N} V_{i} \geq 0 \\
0 \text { if } V_{a}-\sum_{i=1}^{N} V_{i} \leq 0
\end{array} .\right.
$$

Notice that if $V_{a}-\sum_{i=1}^{i=N} V_{i}=0$ it does not matter if the project is approved or not.

We restrict ourselves to a fair social choice function. By fairness it is meant that in case that the project is disapproved (i.e., $d=0$ ) no transfers from Player $a$ to the other players are made (i.e., $T_{i}=0$ ) whereas, if the project is undertaken each player is fully compensated (i.e., $T_{i}=V_{i}$ ). This implies that a function $f$ is fair if it satisfies the following requirements: $\forall i, U_{i}\left(f(V), V_{i}\right)=0$, and $U_{a}\left(f(V), V_{a}\right) \geq 0$.

The problem is that the government official has to make a central planner decision without knowing the net benefit of Player $a$ and the cost borne by each of the other individuals. Therefore, he has to design a mechanism that induces the players to reveal their information about the benefit and the costs resulting from the project under consideration. Our objective is to present a simple (decentralized) sequential mechanism that, instead of inducing the players to reveal to the government their benefit and costs, induces the beneficiary Player $a$ to apply for and undertake only efficient projects, as well as fully compensate each of the individuals adversely affected by the execution of the project. 


\section{The mechanism for $\mathrm{N}=1$}

Let us consider first the case with one beneficiary denoted $a$ and one costbearing individual denoted $b$. The sequential mechanism is defined as follows (see Figure 1).

Stage 1: Player $a$ has two options: apply or not for the license to undertake the indivisible project. If s/he does not apply, the project is not undertaken and the utility of each player is zero. If Player $a$ applies, s/he has to announce the cost imposed by the project on Player $b, T_{b}, T_{b} \in \mathfrak{R}_{+}$. Proceed to stage 2 .

Stage 2: Player $b$ can confirm or not the announcement of Player $a$. If s/he confirms, Player $a$ transfers to Player $b$ the declared amount $T_{b}$ and $\mathrm{s} / \mathrm{he}$ has to decide whether to carry out the project $(d=1)$ or not $(d=0)$. After these two decisions of Player $a$ the game ends. Notice that, regardless of Player $a$ 's second decision, s/he has to pay Player $b$ the amount $T_{b}$. Therefore, the resulting utilities when $d=1$ and $d=0$ are equal, respectively, to $\left(U_{a}, U_{b}\right)=\left(V_{a}-T_{b}, T_{b}-V_{b}\right)$ and $\left(U_{a}, U_{b}\right)=\left(-T_{b}, T_{b}\right)$.

If Player $b$ does not confirm the announcement of Player $a$, s/he has to make an alternative declaration, $T_{b}^{\prime}$, regarding the cost s/he bears due to the project, where $T_{b}^{\prime}>T_{b}$. That is, s/he can only claim that Player $a$ 's announced cost is underestimated. Proceed to stage 3.

Stage 3: Given the alternative higher cost declared by Player $b$, Player $a$ can either regret, i.e., decide not to undertake the project s/he applied for, or pass the privilege to decide on the execution of the project to Player $b$. In the former case (of regret) Player $a$ has to pay Player $b$ an amount $\delta>0$ for bothering him. The resulting utilities in this situation are $\left(U_{a}, U_{b}\right)=(-\delta, \delta)$. In the latter case, the game proceeds to stage 4 .

Stage 4: Player $b$ either approves the application of Player $a$ or disapproves it. In the former case, Player $a$ can undertake the project without compensating Player $b$. This ensures that Player $a$ undertakes the project. The resulting utilities in this situation are $\left(U_{a}, U_{b}\right)=\left(V_{a},-V_{b}\right)$. In the latter case that Player $b$ disapproves Player $a$ 's application, the project is not undertaken and both players are punished for "bothering" the government official. The fines that Player $a$ and Player $b$ pay to the 
government are equal, respectively, to $2 \delta$ and $T_{b}^{\prime}$ (Notice that Player $b$ 's fine depends on her/his earlier declaration in stage 2). The resulting utilities are equal to $\left(U_{a}, U_{b}\right)=\left(-2 \delta,-T_{b}^{\prime}\right)$.

\section{Insert Figure 1 here}

The following proposition establishes that the unique outcome of the subgameperfect Nash equilibrium is efficient and fair.

Proposition 1: The unique subgame-perfect Nash equilibrium of the game satisfies the following conditions:

1. If $V_{a}-V_{b}<0$, then Player $a$ does not apply for the license.

2. If $V_{a}-V_{b}>0$, then Player $a$ applies for the license and carries out the project as well as fully compensates Player $b$.

3. If $V_{a}-V_{b}=0$, then Player $a$ is indifferent between not applying and between applying, proceeding, and fully compensating.

\subsection{The analysis of the mechanism}

How does this sequential mechanism work? Using the solution concept of subgame perfect Nash equilibrium, we start by solving for the optimal choice of the last mover, Player $b$, for each possible situation s/he might face, and then work backward to determine the optimal choice for the other player, Player $a$, who makes a decision in the earlier stage.

Suppose that in stage 1, Player $a$ applies for a license and announces $T_{b}<V_{b}$ (s/he under-reports Player $b$ 's cost). Then it is optimal for Player $b$ to challenge Player $a$ by declaring $T_{b}^{\prime}$, such that, $T_{b}<T_{b}^{\prime}<V_{b}$. Player $a$ knows then that if s/he passes the privilege to decide on the execution of the project to Player $b$ her/his utility will be $-2 \delta$. This is because Player $b$ 's decision will be to disapprove the license application and thereby increase her/his utility from $-V_{b}$ to $-T_{b}^{\prime}$. Therefore, Player $a$, in stage 3 , will give up the project, in which case, her/his utility increases from $-2 \delta$ to $-\delta$. The utilities of the players in this case are equal to $\left(U_{a}, U_{b}\right)=(-\delta, \delta)$. Notice that if, in stage 2, Player $b$ confirms the cost announcement of Player $a$, 
instead of challenging her/him, then Player $a$ will carry out the project in stage 2, in which case Player $b$ 's utility will be $T_{b}-V_{b}<0$, which is lower than $\delta$.

Now suppose that in stage 1, Player $a$ applies for a license and announces $T_{b} \geq V_{b}$ (s/he over-reports Player $b$ 's cost). In this case, it is optimal for Player $b$ to approve Player $a$ 's announcement, already in stage 2, and this induces Player $a$ to undertake the project and receive the benefit $V_{a}-T_{b}$. The resulting utility of Player $b$ is $T_{b}-V_{b}$ (if instead of approving Player $a$ 's declaration, Player $b$ challenges Player $a$ by declaring $T_{b}^{\prime}$, such that $T_{b}^{\prime}>T_{b} \geq V_{b}$, then Player $a$ would have passed the privilege to decide to Player $b$, realizing that Player $b$ would approve the license application, in which case her/his utility increases from $-T_{b}^{\prime}$ to $-V_{b}$. But $-V_{b}$ is still lower than Player $b$ 's utility from approving Player $a$ 's announcement already in stage 2, $\left.T_{b}-V_{b}\right)$. In this case then, the players' utilities are $\left(U_{a}, U_{b}\right)=\left(V_{a}-T_{b}, T_{b}-V_{b}\right)$.

To sum up, taking into account the optimal behavior of Player $b$ in stage 2 and 4, in stage 1 Player $a$ can choose one of the following three strategies:

(i) Do not apply for a license to undertake the project. In this case, her/his utility is zero, (ii) Apply for a license and under-report Player b's cost, $T_{b}<V_{b}$. In this case, Player $b$ challenges Player $a$ inducing him not to proceed with the project and obtain the utility $-\delta$. (iii) Apply for a license and make a truthful announcement or overreport, $T_{b} \geq V_{b}$. In this case, Player $b$ approves the cost announcement of Player $a$, already in stage 2, inducing Player $a$ to undertake the project and compensate him according to Player $a$ 's announcement. In this case Player $a$ 's utility is $V_{a}-T_{b}$. This implies that it is preferable for Player $a$ to make a truthful report, i.e., declare $T_{b}=V_{b}$ and have a utility of $V_{a}-V_{b}$. It is clear that strategy (i) dominates strategy (ii) and therefore, Player $a$ never chooses strategy (ii). However, if $V_{a}-V_{b}>0$, then strategy (iii) dominates strategy (i) and vice versa, if $V_{a}-V_{b}<0$. We have therefore obtained that, if $V_{a}-V_{b}>0$, then it is optimal for Player $a$ to apply for a license, make a truthful cost announcement and undertake the project. If, however, $V_{a}-V_{b}<0$, then it is optimal for Player $a$ not to apply for a license. The resulting utilities in these two 
possible cases are equal, respectively, to $\left(U_{a}, U_{b}\right)=\left(V_{a}-V_{b}, 0\right)$ and $\left(U_{a}, U_{b}\right)=(0,0) .^{3}$

\section{Extension to the case of $N>1$ cost-bearing players}

The sequential mechanism is modified as follows (see Figure 2).

Stage 1: Player $a$ has two options: apply or not for the license to undertake the indivisible project. If s/he does not apply, the project is not undertaken and the utility of each player is zero. If Player $a$ applies, s/he has to announce the cost imposed by the project on each of the $N$ players $\underline{T}=\left(T_{1}, \ldots, T_{N}\right)$, where $\underline{T} \in \mathfrak{R}_{+}^{N}$. Proceed to stage 2.

Stage 2: The social planner randomly selects one player, indexed $c$, among the $N$ cost-bearing individuals. Player $c$ can confirm the announcement of Player $a$ or not. If s/he confirms, Player $a$ transfers to each player $i$ the declared amount, $T_{i}$ and s/he has to decide whether to carry out the project $(d=1)$ or not $(d=0)$. After these two decisions of Player $a$ the game ends. Notice that regardless of Player $a$ 's second decision, Player $a$ has to pay each player $i$ the amount $T_{i}$. Therefore, the resulting utilities when $d=1$ and $d=0$ are, respectively:

$$
\begin{aligned}
& \left(U_{a}, U_{1}, \ldots, U_{N}\right)=\left(V_{a}-\sum_{i=1}^{i=N} T_{i}, T_{1}-V_{1}, \ldots, T_{N}-V_{N}\right) \text { and } \\
& \left(U_{a}, U_{1}, \ldots, U_{N}\right)=\left(-\sum_{i=1}^{i=N} T_{i}, T_{1}, \ldots, T_{N}\right) .
\end{aligned}
$$

If Player $c$ does not confirm the announcement of Player $a$, s/he has to choose one player, indexed $b$, among the $N$ cost-bearing individuals (it might even be s/he herself/himself). Proceed to stage 3.

Stage 3: Player $b$ can either disagree or agree with Player $c$. If s/he disagrees, Player $c$ has to pay the social planner a fine $\delta$, and Player $a$ has to transfer to each player $i$ the amount declared in stage $1, T_{i}$ and $\mathrm{s} /$ he has to decide whether to carry out the project $(d=1)$ or not $(d=0)$. After these two decisions of Player $a$ the game ends. Notice that, regardless of Player $a$ 's second decision, s/he has to pay each player

\footnotetext{
${ }^{3}$ When $V_{a}-V_{b}=0$, Player $a$ is indifferent between not applying for a license and applying, making a truthful cost announcement and undertaking the project. This is because in both cases his utility is zero.
} 
$i$ the amount $T_{i}$. Therefore, the resulting utilities when $d=1$ and $d=0$ are, respectively: $\left(U_{a}, U_{1}, \ldots, U_{c}, \ldots, U_{N}\right)=\left(V_{a}-\sum_{i=1}^{i=N} T_{i}, T_{1}-V_{1}, \ldots, T_{c}-V_{c}-\delta, \ldots, T_{N}-V_{N}\right)$ and $\left(U_{a}, U_{1}, \ldots, U_{c}, \ldots, U_{N}\right)=\left(-\sum_{i=1}^{i=N} T_{i}, T_{1}, \ldots, T_{c}-\delta, \ldots, T_{N}\right)$.

If Player $b$ agrees with Player $c$, s/he has to make an alternative declaration $T_{b}^{\prime}$, regarding the cost s/he bears due to the project, where $T_{b}^{\prime}>T_{b}$. That is, s/he can only claim that Player $a$ 's announced cost is under-estimated. Proceed to stage 4.

Stage 4: Given the alternative higher cost declared by Player $b$, Player $a$ can either regret i.e., decide not to undertake the project, and compensate Player $b$ and Player $c$ for bothering them, by paying them, respectively, an amount $\delta>0$ and $T_{c}$, ending the game with the utilities $\left(U_{a}, U_{b}, U_{c}, \ldots, U_{N}\right)=\left(-T_{c}-\delta, \delta, T_{c}, \ldots, 0\right)$, or to pass the privilege to decide to Player $b$. Proceed to stage 5 .

Stage 5: Player $b$ either approves the application of Player $a$ or disapproves it. In the former case, Player $a$ can undertake the project without compensating the other players. This ensures that Player $a$ undertakes the project. The resulting utilities in this situation are: $\left(U_{a}, U_{b}, U_{c}, \ldots, U_{N}\right)=\left(V_{a},-V_{b},-V_{c}, \ldots,-V_{N}\right)$. In the latter case that Player $b$ disapproves Player $a$ 's application, the project is not undertaken and players $a$ and $b$ are punished for "bothering" the government official. The fines that players $a$ and $b$ pay to the government are equal, respectively, to $T_{c}+2 \delta$ and $T_{b}^{\prime}$ (the fine levied on Player $b$ depends on her/his earlier declaration in stage 3). The game ends with the utilities $\left(U_{a}, U_{b}, U_{c}, \ldots, U_{N}\right)=\left(-T_{c}-2 \delta,-T_{b}^{\prime}, 0, \ldots, 0\right)$.

Notice that the suggested mechanism does not require any knowledge of the cost-bearers about the beneficiary's net reward from the project. Thus, no beliefs about the value of this net reward is needed and the concept of Subgame Perfect equilibrium is the appropriate one.

\section{Insert Figure 2 here}

Proposition 2: The unique sub-game perfect Nash equilibrium of the game satisfies the following conditions:

1. If $V_{a}-\sum_{i=1}^{i=N} V_{i}<0$, then Player $a$ does not apply for the license. 
2. If $V_{a}-\sum_{i=1}^{i=N} V_{i}>0$, then Player $a$ applies for the license ,carries out the project as well as fully compensates the other players.

3. If $V_{a}-\sum_{i=1}^{i=N} V_{i}=0$, then Player $a$ is indifferent between not applying and between applying, proceeding, and fully compensating.

Proof: Using backward induction, we start by solving for the optimal choice of the last mover, Player $b$, for each possible situation s/he might face, and then work backward to compute the optimal choice for the players acting before, Player $c$ and Player $a$.

Suppose that in stage 1 Player $a$ applies for a license and under reports the cost of at least one of the players. Then, as we show in the following, in stage 2, it is optimal for Player $c$ to choose one player among of these players, indexed $b$. Applying the same reasoning as for the case of $N=1$, it follows that Player $b$ 's best response is to challenge Player $a$ by declaring $T_{b}^{\prime}$ such that $T_{b}<T_{b}^{\prime}<V_{b}$. Recall that by adopting this optimal strategy Player $b$ induces Player $a$ to give up the project in stage 3 and receive a utility $-T_{c}-\delta$, which is higher than her/his utility when s/he passes the decision to Player $b$ i.e., $-T_{c}-2 \delta$. The utilities of all players in this case will be $\left(U_{a}, U_{b}, U_{c}, \ldots, U_{N}\right)=\left(-T_{c}-\delta, \delta, T_{c}, 0, \ldots, 0\right)$. If Player $c$, instead of choosing Player $b$, confirms the announcement of Player $a$ her/his utility will be $T_{c}-V_{c}$ which is lower than $T_{c}$. Also, if Player $b$ in stage 3, instead of challenging Player $a$, disagrees with Player $c$ s/he receives $T_{b}-V_{b}<0$ which is lower than $\delta$.

Suppose now that in stage 1 Player $a$ applies and announces $T_{i} \geq V_{i} \quad \forall i$ (s/he over-reports). In this case it is optimal for Player $b$ (or for any other player that Player $c$ will choose) to approve the project already in stage 3 (disagree with Player $c$ ) and this induces Player $a$ to undertake the project and receive the benefit $V_{a}-\sum_{i=1}^{i=N} T_{i}$. The resulting utility of Player $b$ is $T_{b}-V_{b}$. This is because if instead of approving Player $a$ 's declaration, Player $b$ challenges Player $a$ by declaring $T_{b}^{\prime}$, such that $T_{b}^{\prime}>T_{b} \geq V_{b}$. Player $a$, then, would have passed the privilege to decide to Player $\mathrm{b}$, 
realizing that Player $b$ would approve the license application, in which case her/his utility increases from $-T_{b}^{\prime}$ to $-V_{b}$ (the reasoning is the same as in the case of only one cost-bearing individual). But, $-V_{b}$ is still lower than Player $b$ 's utility from approving Player $a$ 's announcement already in stage $3, T_{b}-V_{b}$. Given that in this case, in stage 3, Player b will disagree with Player $c$, the utility of Player $c$ will be $T_{c}-V_{c}-\delta$. Thus, it is preferable for Player $c$ to agree in stage 2 and benefit from a higher utility $T_{c}-V_{c}$. To sum up, in the event that Player $a$ announces $T_{i} \geq V_{i} \forall i$, it is optimal for Player $c$ to agree in stage 2, and the resulting utilities will be $\left(U_{a}, U_{1}, \ldots, U_{N}\right)=\left(V_{a}+\sum_{i=1}^{i=N} T_{i}, V_{1}-T_{1}, \ldots, V_{N}-T_{N}\right)$.

To sum up, taking into account the optimal behavior of Player $b$ in stages 3 and 5, and of Player $c$ in stage 2, Player $a$ can choose one of the following three strategies:

(i) Do not apply for a license to undertake the project. In this case, her/his utility is zero, (ii) Apply for a license and under-report the cost of at least one of the players indexed $b, T_{b}<V_{b}$. In this case, in stage 2, Player $c$ will choose Player $b$ and the latter will challenge Player $a$ inducing her/him, in stage 4, not to proceed with the project and obtain the utility $-T_{c}-\delta$. (iii) Apply for a license and make a truthful announcement or over-report, $T_{i} \geq V_{i} \forall i$. In this case, Player $c$ will approve the project in stage 2 inducing Player $a$ to undertake the project and compensate all the players including her/him according to Player $a$ 's announcement. In this case, Player $a$ 's utility is $V_{a}-\sum_{i=1}^{i=N} T_{i}$. Thus, it is preferable for Player $a$ to make a truthful report i.e., declare $T_{i}=V_{i} \forall i$ and have the utility $V_{a}-\sum_{i=1}^{i=N} V_{i}$. It is clear that strategy (i) dominates strategy (ii) and therefore, Player $a$ will never chooses strategy (ii). However, if $V_{a}-\sum_{i=1}^{i=N} V_{i}>0$ strategy (iii) dominates strategy (i) and vice versa if $V_{a}-\sum_{i=1}^{i=N} V_{i}<0$. We have therefore obtained that, if $V_{a}-\sum_{i=1}^{i=N} V_{i}>0$, then it is optimal for Player $a$ to apply for a license, make a truthful cost announcement and undertake 
the project. If, however, $V_{a}-\sum_{i=1}^{i=N} V_{i}<0$, then it is optimal for $a$ not to apply for a license. The resulting utilities in these two possible cases are equal, respectively, to $\left(U_{a}, U_{1}, \ldots, U_{N}\right)=\left(V_{a}-\sum_{i=1}^{N} V_{i}, 0, \ldots, 0\right) \quad$ and $\quad\left(U_{a}, U_{1}, \ldots, U_{N}\right)=(0,0, \ldots, 0)$. When $V_{a}-\sum_{i=1}^{i=N} V_{i}=0$ Player $a$ is indifferent between not applying for a license and applying, making a truthful cost announcement and undertaking the project. This is because in both cases her/his utility is zero.

\section{Conclusion}

In this paper, we propose a simple sequential mechanism whose subgameperfect Nash equilibrium efficiently and equitably implements a multiple-cost-singlebenefit project under unilateral information. The mechanism can be viewed as being complementary to Coase's solution to the problem of negative externalities since it provides a structure for negotiation between the players on the appropriate compensation under "unilateral" information in a dichotomous setting. The structure of negotiation is as follows: In the first stage of the five-stage mechanism, if the single beneficiary applies for the project, she/he must propose an allocation of compensation to all the cost bearers. In the second stage, a randomly selected cost bearer can challenge the single beneficiary by stating the name of a cost bearer who is not being fully compensated. If that player is indeed being under-compensated, she/he can challenge the single beneficiary by proposing an alternative higher compensation for her/him. Given this demand for compensation, the single beneficiary can either regret and not undertake the project or pass the decision on to the chosen under-compensated cost bearer. The mechanism induces the single beneficiary to apply for and undertake the project only if her/his net benefit from the project outweighs the cost it imposes on the other players. Furthermore, the proposed mechanism also induces the beneficiary to fully compensate each of the adversely affected individuals. 


\section{References}

Abreu, D., Sen, A., 1990. Subgame perfect implementation: A necessary and almost sufficient condition. Journal of Economic Theory 50, 285-299.

Admati, A. R., Perry, M., 1991. Joint projects without commitment. Review of Economic Studies 58, 259-276.

Arrow, K., 1970. The Organization of Economic Activity: Issues Pertinent to the Choice of Market versus Non-market Allocation, in: Haveman, R. H., Margolis, J. (Eds.) Public Expenditures and Policy Analysis, Markham,Chicago, 59-73.

Bagnoli, M., Lipman, B.L., 1989. Provision of public goods: Fully implementing the core through private contributions. Review of Economic Studies 56, 583-602.

Bagnoli, M., Lipman, B.L., 1992. Private provision of public goods can be efficient. Public Choice 74, 59-78.

Clarke, E., 1971. Multipart pricing of public goods. Public Choice 11, 17-33.

Coase, R., 1960. The problem of social cost. Journal of Law and Economics 3, 1- 44.

Duggan, J., Roberts, J., 2002. Implementing the efficient allocation of pollution. American Economic Review 92, 1070-1078.

English, D., Yates, A., 2007. Citizens' demand for permit and Kwerel's incentive compatible mechanism for pollution control. Economics Bulletin 17, 1-9.

Gradstein, M., Nitzan, S., 1990. Binary participation and incremental provision of public goods. Social Choice and Welfare 7, 171-192.

Groves, T., 1973. Incentives in teams. Econometrica 41, 617-631.

Herrero, M. J., Srivastava S., 1992. Implementation via backward induction. Journal of Economic Theory 56, 70-88.

Jackson, M., Moulin, H., 1992. Implementing a public project and distributing its cost. Journal of Economic Theory 57, 125-140.

Kahana , N ., Mealem , Y., Nitzan, S., 2008. A complete implementation of the efficient allocation of pollution. Economics Letters 101, 142-144.

Kwerel, E., 1977. To tell the truth: Imperfect information and optimal pollution control. Review of Economic Studies 44, 595-601.

Lewis, T. R., Sappington, D. E.M., 1995. Using markets to allocate pollution permits and other scarce resource rights under limited information. Journal of Public Economics 57, 431-455.

Maniquet, F., 2003. Implementation of allocation rules under perfect information.

Social Choice and Welfare 21, 323-346. 
Moore, J., Repullo, R., 1988. Subgame perfect implementation. Econometrica 56, 1191-1220.

Mutuswami, S., Winter, E., 2004. Efficient mechanisms for multiple public goods. Journal of Public Economics 88, 629-644.

Palfrey, T. R., Rosenthal, H., 1984. Participation and the provision of discrete public goods: A strategic analysis. Journal of Public Economics 24, 171-193.

Pigou, A. C., 1920. The Economics of Welfare. Macmillan, London.

Varian, H. R., 1994. A solution to the problem of externalities when agents are well-informed. American Economic Review 84, 1278-1293. 
Figure 1-The Mechanism for $\mathrm{N}=1$

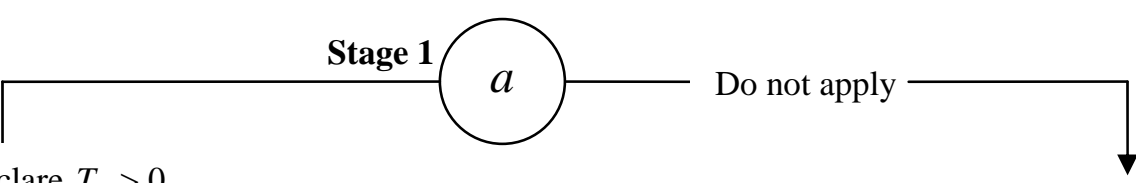

Apply and declare $T_{b}>0$

$$
\left(U_{a}, U_{b}\right)=(0,0)
$$

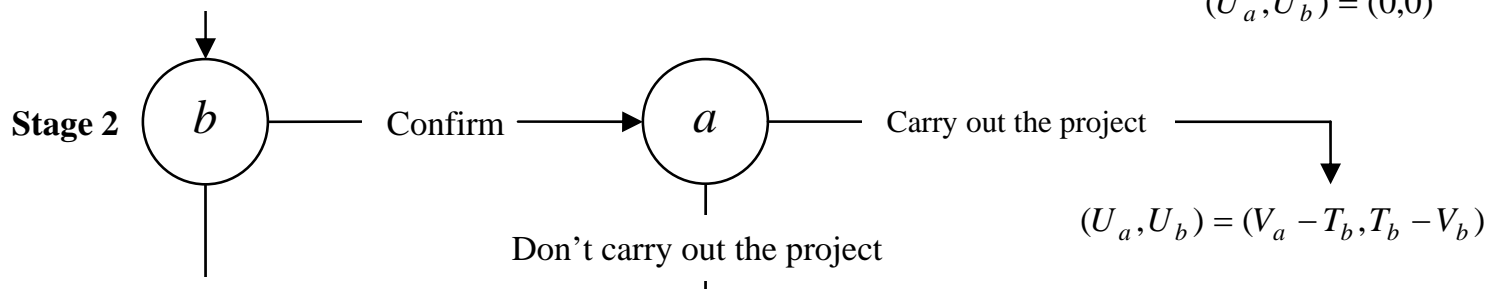

Declare $T_{b}^{\prime}>T_{b}$

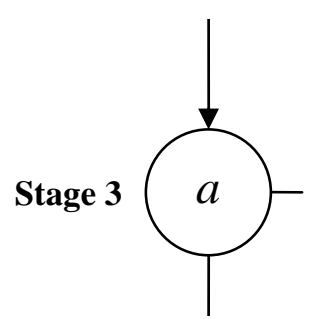

Don’t carry out the project

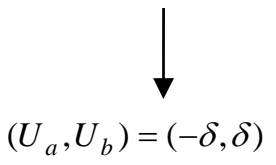

Pass the decision on to $b$

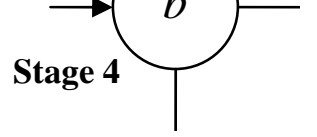

Approve the project

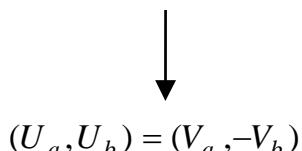

Disapprove the project

$$
\left(U_{a}, U_{b}\right)=\left(-2 \delta,-T_{b}^{\prime}\right)
$$
$\left(U_{a}, U_{b}\right)=(-\delta, \delta)$
$\left(U_{a}, U_{b}\right)=\left(V_{a},-V_{b}\right)$ 


\section{Figure 2-The Mechanism for $\mathrm{N}>1$}

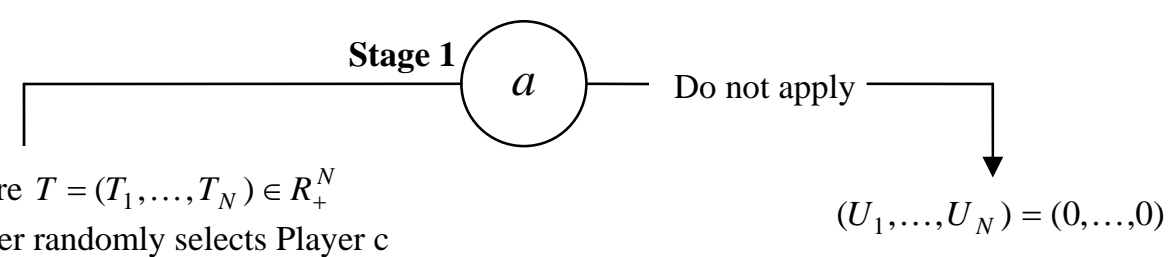

Apply and declare $T=\left(T_{1}, \ldots, T_{N}\right) \in R_{+}^{N}$

The social planner randomly selects Player c

$$
\left(U_{1}, \ldots, U_{N}\right)=(0, \ldots, 0)
$$

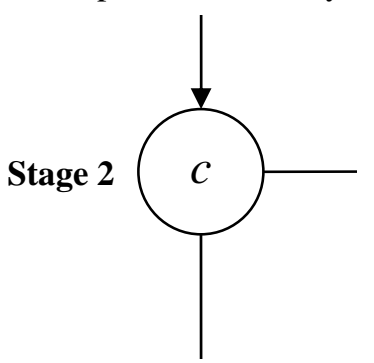

Choose a player $b$

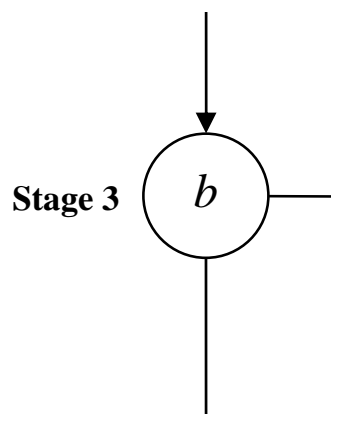

Declare $T_{b}^{\prime}>T_{b}$

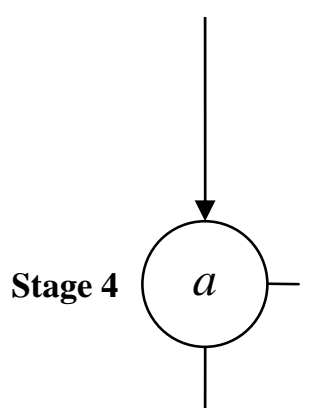

Don't carry out the project

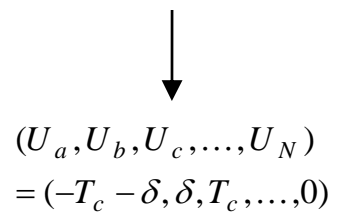

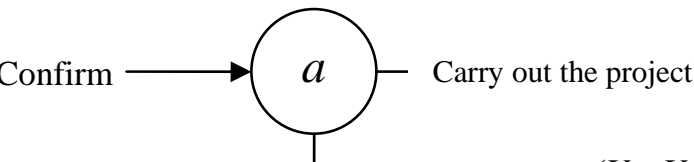

Don't carry out the project

$$
\begin{aligned}
& \left(U_{a}, U_{1}, \ldots, U_{N}\right) \\
& =\left(V_{a}-\sum_{i=1}^{i=N} T_{i}, T_{1}-V_{1}, \ldots, T_{N}-V_{N}\right)
\end{aligned}
$$

$$
\begin{aligned}
& \left(U_{a}, U_{1}, \ldots, U_{N}\right) \\
& =\left(-\sum_{i=1}^{i=N} T_{i}, T_{1}, \ldots, T_{N}\right)
\end{aligned}
$$

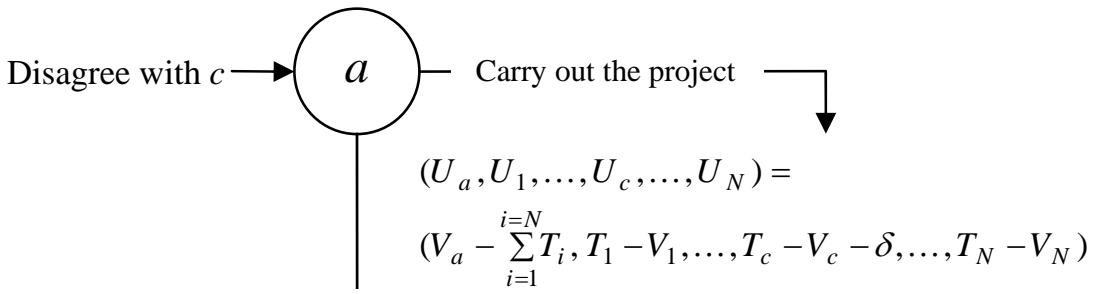

Don't carry out the project

$$
\begin{aligned}
& \left(U_{a}, U_{1}, \ldots, U_{c}, \ldots, U_{N}\right) \\
& =\left(-\sum_{i=1}^{i=N} T_{i}, T_{1}, \ldots, T_{c}-\delta, \ldots, T_{N}\right)
\end{aligned}
$$
Pass the decision
on to $b$

Stage 5

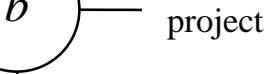

Approve the project

$$
\left(U_{a}, U_{b}, U_{c}, \ldots, U_{N}\right)
$$

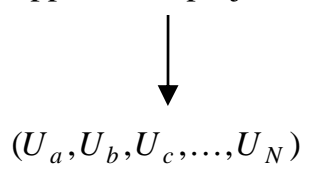

$=\left(V_{a},-V_{b},-V_{c}, \ldots,-V_{N}\right)$ 